\title{
Study on the Surface Condition of Composite Biomaterials Related to Saliva $p H$
}

\author{
IRINA GRADINARU1 ${ }^{1}$, LEONARD IGNAT ${ }^{2}$, LEVENTE-CRISTIAN GIURGIU ${ }^{1}$, \\ CRISTINA GENA DASCALU ${ }^{3 *}$, LOREDANA LILIANA HURJUI ${ }^{3 *}$, \\ MAURUSA-ELENA IGNAT ${ }^{2}$, FLORICA DOROFTEI ${ }^{2}$, ZINOVIA SURLARI ${ }^{*} *$ \\ SILVIA FOTEA ${ }^{4}$, GABRIELA GURAU ${ }^{4}$, ADRIAN BEZNEA ${ }^{4}$, \\ MAGDA-ECATERINA ANTOHE ${ }^{1}$
}

${ }^{1}$ Grigore T. Popa University of Medicine and Pharmacy, Faculty of Dental Medicine, 16 University Str., 700115, Iasi, Romania

${ }^{2}$ Petru Poni Institute of Macromolecular Chemistry, Centre of Advanced Research in Bionanoconjugates and Biopolymers, 41A Grigore Ghica Voda Alley, 700487 Iasi, Romania

${ }^{3}$ Grigore T. Popa University of Medicine and Pharmacy, Faculty of Medicine, 16 University Str., 700115, Iasi, Romania

${ }^{4}$ Dunarea de Jos University of Galati, Faculty of Medicine and Pharmacy, 47 Domneasca Str., 800008, Galati, Romania

\begin{abstract}
In the context of an extremely diverse offer of composite materials, the clinical reality permanently offers data about the way in which the individual feeding behavior, correlated with the salivary structure definitely have an impact on the structure, namely the quality of fillings made of various composite materials. The purpose of this study is represented by the analysis of the behavior of 6 types of composite materials that are frequently used in the dental medical practice in the presence of an acidic $\mathrm{pH}$. The composite materials analyzed were Premise (Kerr) - P1, Polofil Supra (Voco) - P2, Nexcomp (Meta Biomed) - P3, Point 4 (Kerr) - P4, Pekalite (Heraeus Kulzer) - P5, and Progress (K.B. Mutsumi) - P6. The images of scanning electron microscopy clearly indicate that all samples are affected by acidic conditions ( $\mathrm{pH} 4$ ) after a moderately, but continuous exposure of 3 months. Signs of abrasions structural deterioration and leaks are obvious after pH 4 saliva treatments within all samples and magnifications, being marked by texture decay, rust-like presentation, and shallows, holes and cracks rise and enlargement. The intensity of deterioration processes varies between the studied commercial samples, with Pekalite (Heraeus Kulzer) followed by Point 4 (Kerr) being the most resistant to degradation in the current experimental conditions.
\end{abstract}

Keywords: dental composite, salivapH, surfaceanalysis, SEM

\section{Introduction}

Dental restoration materials represented by dental composites are the result of massive research in the field of biomaterials, in the attempt to reach the ideal substitution formula for the biological tissue, both with regard to functionality and esthetics. For composite materials designed for restorations in the posterior areas of the arch, mostly subject to masticatory forces, an important objective is represented by the necessity of permanent improvement of mechanical properties, through the diversification of the structural architecture to reduce the contraction of polymerization, as well as the stress induced by polymerization, while limiting to a maximum thermal expansion, the risk of ablation and fracture, respectively. The essential underlying aspects in the structural evolution of dental composites are represented by the identification and limitation of the factors that reduce the life span of restorations [1].

The structure of composite materials reunites 3 distinct stages, each with its own role in dictating the properties of the material the polymerizable resin or organic component, the filling or the inorganic component and the filling-resin interface, represented by the coupling agent. The resin stage is composed of polymerizablemonomers that transform from a liquid into a strong crosslinked polymer at exposure

*email: cristina.dascalu@umfiasi.ro; loredana.hurjui@umfiasi.ro 
to visible light, which catalyzes the formation of active centers, usually radicals, which induce polymerization [2]. The inorganic stage plays several parts, among which we can list the improvement of radio-opacity, the modification of the thermal expansion behavior and the reduction of polymerization contraction by the reduction of the resin ratio [3].

The filling-resin interface serves as a bridge by coupling the polymerizable components to the particles surface. An important characteristic of dental composites, especially those designed for frontal restorations, is represented by the chromatic stability of diacrylic resins, this parameter being ensured by the presence in the structure of these biomaterials of certain agents that absorb ultraviolet radiations, as in their absence there could appear alterations of the chromatics under the action of ultraviolet light [4].

The filling content of composite materials is determined by the size of the filling particles and the technology of their embedding in the organic stage. With modern hybrid composites, the preponderant size of the filling particles is between the $0.1-1$ micrometerintervals, the materials being known as micro-hybrids [5]. The size of the filling particles is a decisive factor regarding the long-term behavior of composite restorations, especially the wear resistance, this quality being influenced by the particularities of the clinical case [6].

In the context of an extremely diverse offer of composite materials, the clinical reality permanently offers data about the way in which the individual feeding behavior, correlated with the salivary structure definitely have an impact on the structure, namely the quality of fillings made of various composite materials [7-9].The purpose of this study is represented by the analysis of the behavior of 6 types of composite materials that are frequently used in the dental medical practice in the presence of an acidic $p \mathrm{H}$.

\section{Materials and methods}

The composite materials analyzed were Premise (Kerr)- P1, Polofil Supra (Voco)-P2, Nexcomp (Meta Biomed)-P3, Point 4 (Kerr)-P4, Pekalite (Heraeus Kulzer)-P5, and Progress (K.B. Mutsumi)-P6 (Figure 1).

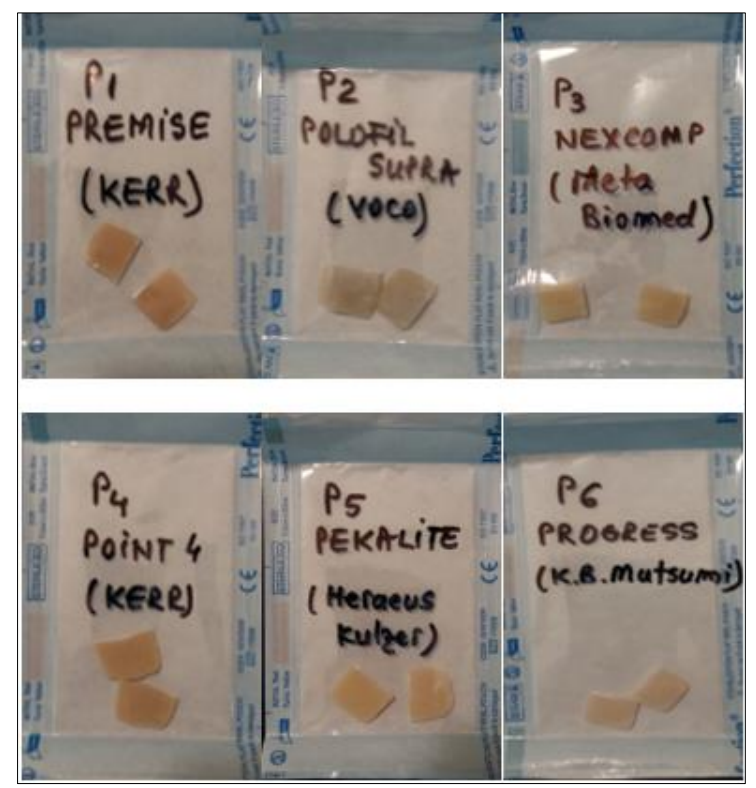

Figure 1.The visual presentation of analyzed composite materials

Premise is a composite material that associates the accomplishments of nanotechnology with the avantgarde idea of a trimodal obturation material and pressed resins, which lead to the smallest setting contraction among traditional composite materials, in corroboration with an excellent mechanical resistance. This composite contains a mix of 3 types of filling - a trimodal structure based on silica 
particles of 0.02 microns in diameter, particles of barium glass of 0.4 microns. The large size of the latter increases the saturation degree of the material with filling particles, whereas small particles ensure the creation of a material with an esthetic that matches the best micro-hybrid composites.

Polofil Supra, a photopolymerizable restoration material of micro-hybrid type, is recommended in the reconstruction of damaged anterior teeth, following various traumatisms. By its structure, this biomaterial combines the advantages of composites with micro- and macro-filler with an increased abrasion resistance and stability over time of the nuances, in association with low contraction and water absorption.

Nexcomp is a nano-hybrid composite characterized by low compression (1.6\%) for superior marginal integrity, it has fillings of about 40 nanometers, and is recommended in class I, II, III, IV, V restorations. The composition includes polymer-based organic components, Bis-GMA(bisphenol Aglycidyl methacrylate), UDMA(urethane di-methacrylate), Bis-EMA (ethoxylated bisphenol A glycol dimethacrylate), as well as ceramic borosilicate. The size of inorganic filling particles fit into the following values: $0.04-07 \mu \mathrm{m}$, with a volume of total quantity of inorganic filling particles of $54 \%$.

The structure of the Point 4 composite reunites as organic resin components Bis-GMA, TEGDMA (triethylene glycol dimethacrylate) and Bis-EMA, all together with barium and silica filling. The average size of particles is of 0.4 microns at a loading of $76 \%(\mathrm{w} / \mathrm{w}$ ) or $57 \%$ (by volume).

Pekaliteis a photopolymerizable hybrid micro-glass radio-opaque composite recommended for esthetic restoration in the frontal and lateral area.

Progress, a hybrid photopolymerizable composite, contains nanoparticles and glass microparticles and is pretreated to gain electrostatically attraction, which confers excellent durability of the restoration. It is applied on top of Progress Plus and Progress Flow for anterior and posterior restorations that require an exquisite esthetic. The data regarding the composition of each composite material used, as well as the recommendations for its use are provided by each manufacture.

Test samples of the same size, namely $3 \mathrm{~cm}$ in length, $1.5 \mathrm{~cm}$ wide and $2 \mathrm{~mm}$ thick, were created from each commercial composite material by $20 \mathrm{~s}$ polymerization with the photo-polymerization lamp. The photopolymerization lamp used was Elipar DeepCure-L, manufacturer: 3M, with the following characteristics: wavelength: $430-480 \mathrm{~nm}$, light intensity: $1.470 \mathrm{~mW} / \mathrm{cm}^{2}(-10 \% /+20 \%)$, optical fiber with $360^{\circ}$ rotation, Operation: preset polymerization times $(5 / 10 / 15 / 20 \mathrm{~s})$, continuous mode (120s), tackcure mode. The test samples were made by applying the composite material in silicone conformers of the size mentioned previously, followed by polymerization, so that all test samples subject to analysis should have the same form and size.

Samples were furthermore sectioned in 2 similar halves, one half being introduced in artificial saliva of neutral $p \mathrm{H}$ and the other half in artificial saliva of acidic $p \mathrm{H}$ (Figure 2).

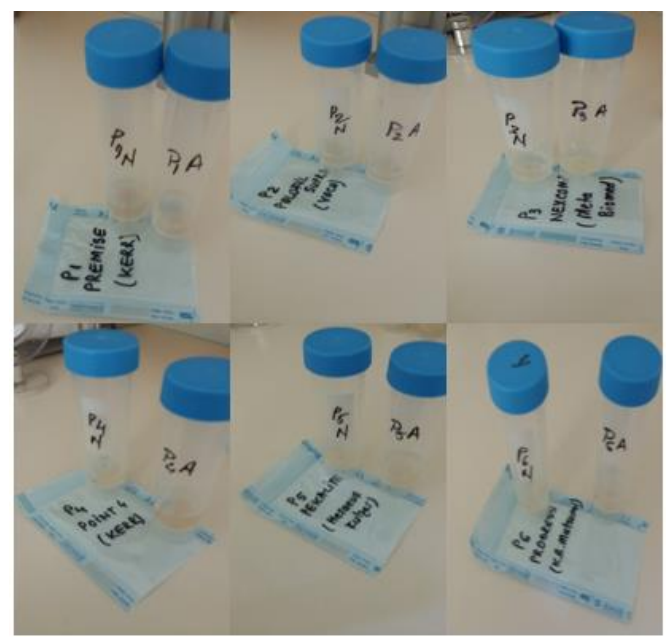

Figure 2. The comparative aspects of samples immersed in saliva with normal and low $\mathrm{pH}$ 
The artificial saliva of neutral $(p \mathrm{H} \mathrm{7)}$ and acidic $p \mathrm{H}(p \mathrm{H} 4)$ were prepared according to the AFNOR S91-141 standard procedure. The components of artificial saliva were as follows: $0.70 \mathrm{~g} / \mathrm{L} \mathrm{NaCl} ; 1.20$ $\mathrm{g} / \mathrm{L} \mathrm{KCl} ; 0.26 \mathrm{~g} / \mathrm{L} \mathrm{Na}_{2} \mathrm{HPO}_{4} ; 1.50 \mathrm{~g} / \mathrm{L} \mathrm{NaHCO} 3 ; 0.33 \mathrm{~g} / \mathrm{L} \mathrm{KSCN} ; 1.35 \mathrm{~g} / \mathrm{L}$ Urea $\left(\mathrm{CH}_{4} \mathrm{~N}_{2} \mathrm{O}\right)$ for $p \mathrm{H} 7$ after solution mixing, respective $400 \mathrm{mg} / \mathrm{L} \mathrm{NaCl} ; 400 \mathrm{mg} / \mathrm{L} \mathrm{KCl} ; 795 \mathrm{mg} / \mathrm{L} \mathrm{CaCl} \cdot \mathrm{H}_{2} \mathrm{O} ; 690 \mathrm{mg} / \mathrm{L}$ $\mathrm{Na}_{2} \mathrm{H}_{2} \mathrm{PO}_{4} \cdot \mathrm{H}_{2} \mathrm{O} ; 300 \mathrm{mg} / \mathrm{L} \mathrm{KSCN} ; 5 \mathrm{mg} / \mathrm{L} \mathrm{Na} 2 \mathrm{~S} \cdot 9 \mathrm{H}_{2} \mathrm{O} ; 1000 \mathrm{mg} / \mathrm{L}$ Urea $\left(\mathrm{CH}_{4} \mathrm{~N}_{2} \mathrm{O}\right)$ for $p \mathrm{H} 4$.

All materials were placed for 3 months at $37^{\circ} \mathrm{C}$ in containers containing normal, and acidic saliva respectively. In the following stage, the test samples were extracted from the saliva recipients, rinsed several times with distilled water and air-dried into an oven at 40 degrees Celsius for $6 \mathrm{~h}$. The morphology of samples treated with neutral and acidic saliva was furthermore analyzed with a scanning electron microscope (SEM) Quanta200(FEI) low vacuum apparatus at various magnification degrees.

\section{Results and discussions}

There are several factors that may trigger deterioration of the composite resins used in dental restoration. Due to the potentially high incidence and impact on both organic and inorganic components from the composite structure, the low $p \mathrm{H}$ medium is a primary factor of decays that occurs trough saliva acidification as result of alimentary and hygiene individual behaviors like food diet and tooth brushing $[10,11]$. The modifications of salivary $p \mathrm{H}$ could be also caused by the influence of bacteria, enzymes, hormones and other factors [12]. A low $p \mathrm{H}$ in saliva may trigger the modification of the surface condition of the composite, filling leakages, may cause discoloration and eventually may create favorable conditions for the development of secondary cavities. In these conditions it is very important from the applicative point of view of dental restoration to know how commercial products behave in time within an acidic environment.

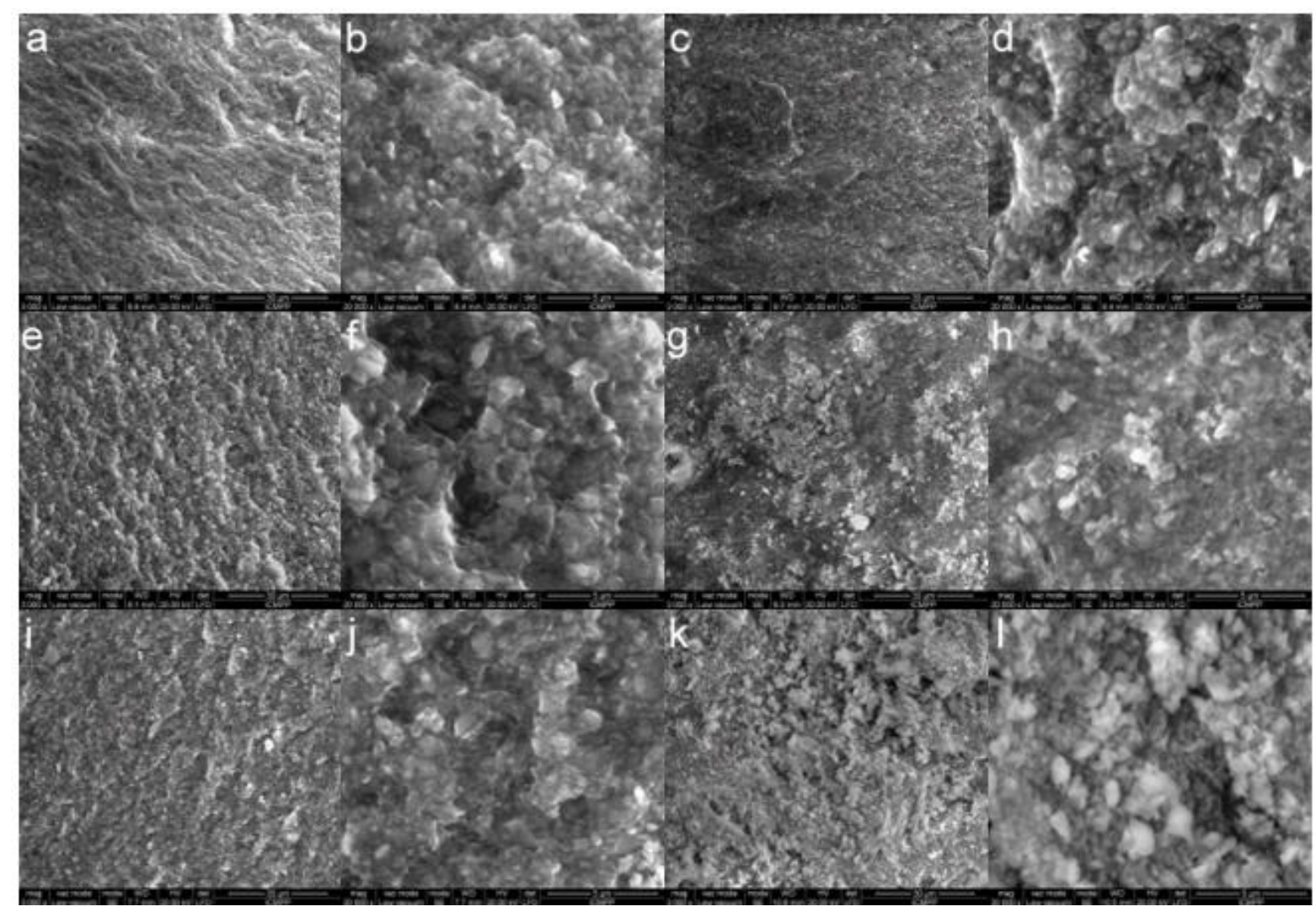

Figure 3. SEM analysis of samples at different magnifications after synthetic saliva treatment at $p \mathrm{H} 7$ (a, b- P1; e, f - P2; i, j - P3) and $p \mathrm{H} 4(\mathrm{c}, \mathrm{d}-\mathrm{P} 1 ; \mathrm{g}, \mathrm{h}-\mathrm{P} 2 ; \mathrm{k}, 1$ - P3) 


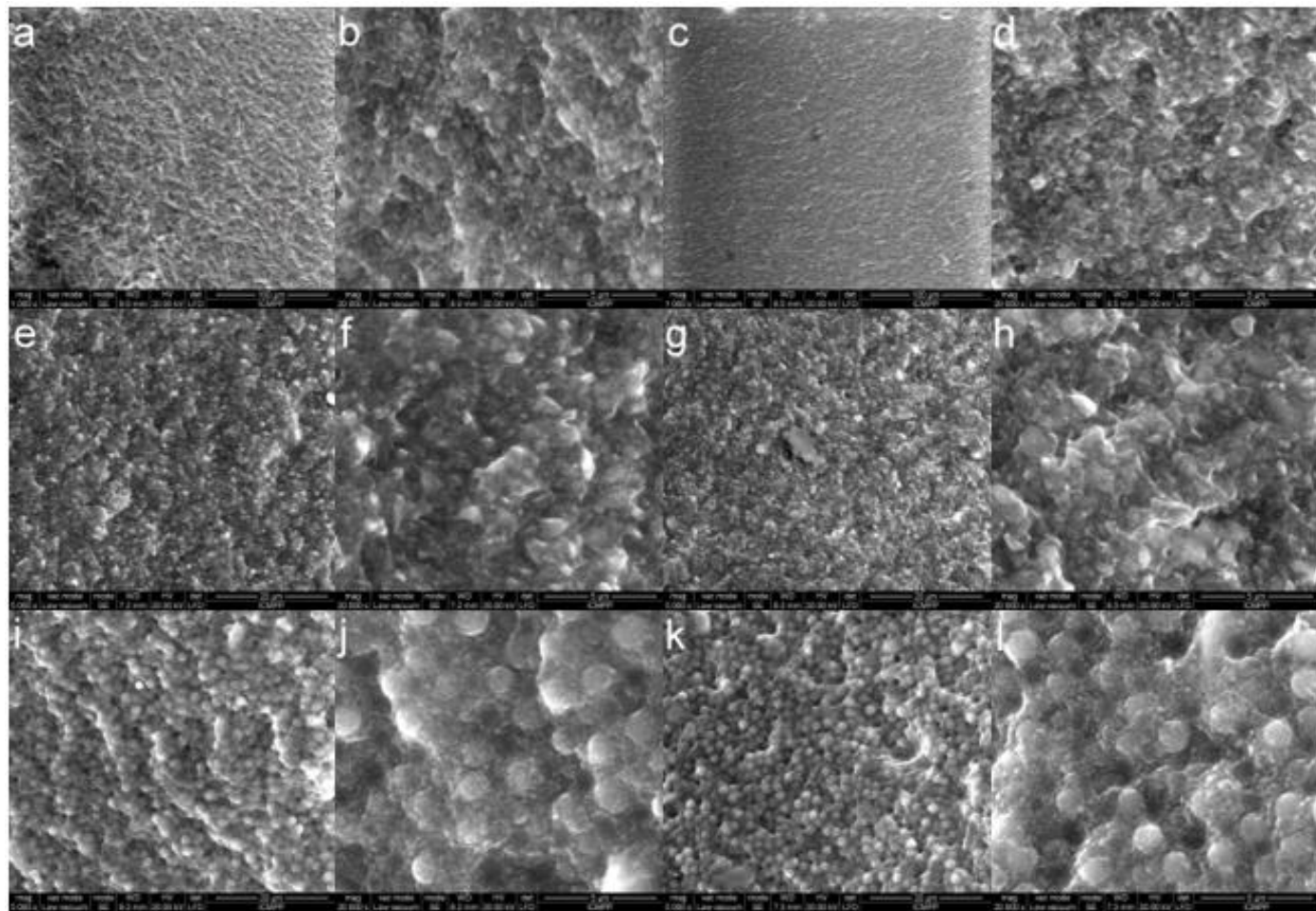

Figure 4. SEM analysis of samples at different magnifications after synthetic saliva

Treatment at $p \mathrm{H} 7$ (a, b- P4; e, f- P5; i, j- P6) and $p \mathrm{H} 4$ (c, d-P4; g, h- P5; k, l- P6)

The surface conditions and morphological changes of selected commercial composite resins P1-P6 after 3 months of immersion in acidic artificial saliva were comparatively evaluated against those subjected to neutral saliva simulated conditions trough SEM imagery (Figure 3-4).

The images of scanning electron microscopyclearly indicate that all samples are affected by acidic conditions $(p \mathrm{H} 4)$ after a moderately, but continuous exposure of 3 months. Signs of abrasionsstructural deterioration and leaks are obvious after $p \mathrm{H} 4$ saliva treatments within all samples and magnifications, being marked by texture decay, rust-like presentation, and shallows, holes and cracks rise and enlargement.

The acid modification of the salivary $p \mathrm{H}$ mainly affects the acrylate resins, were degradation take place through the breakage of polymer chains, with a negative influence on the future resistance of the dental obturation. While these acidic conditions are not reflected in the alteration of the inorganic nanoand micro-fillers from the composite structure, the deterioration of organic resins conducts to filler exposure and eventually outflow. Such processes could beeasily seen particularlyat P6 sample (Figure 4 $\mathrm{k}, \mathrm{l})$ due to its spherical, micron-sized filler particles.

Surface abrasion with filling of lacunar areas and rust-like presentation are main features for P2, indicating a good integrations of filler into the resin matrix, but an extensive loss of polymer chains after their breakdown and formation of salt deposits facilitated by both existing resin and filler. Such a behavior may conduct to brittleness and sudden failure of occlusion.

Samples P1 and P3 also show erosions at surface, combined with the formation of cavities with various depths and extents, accompanied especially at P3 by small pseudo-cracks.

According to the imaging data the P5 samples have achieved the better performance in acidic media, closely followed by $\mathrm{P} 4$, with quitelimited abrasion and gaps formation.

\section{Conclusions}

Six commercial composite materials have been morphological evaluated in regard of their compliance with acidic saliva environment as compared with neutral saliva. It was found that all tested samples were subjected to decays after 3 months of exposure to artificial saliva of $p \mathrm{H} 4$, surfaces being 
affected by various modifications like texture decay, rust-like presentation, with material outflows conducting to erosion, shallows, holes and cracks rise and enlargement. Acidic $p \mathrm{H}$ seems to degrade the composite material in parallel and subsequent chain events that compromise its structural integrity assembled from mixed organic and inorganic components. The intensity of deterioration processes varies between the studied commercial samples, with Pekalite (Heraeus Kulzer) followed by Point 4 (Kerr) being the most resistant to degradation in the current experimental conditions.

\section{References}

1. ALIPING-MCKENZIE M, LINDEN RWA, NICHOLSON JW. The effect of Coca-Cola and fruit juices on the surface hardness of glass-ionomers and compomers. J Oral Rehabil. 2004; 31:1046-1052.

2. BAGHERI R, TYAS MJ, BURROW MF. Subsurface degradation of resinbased composites. Dent Mater. 2007; 23:944-951.

3. BENDERLI Y, GÖKÇE K, KAZAK M. Effect of APF gel on micromorphology of resin modified glass-ionomer cements and flowablecompomers. J Oral Rehabil. 2005; 32:669-675.

4. CAIRNS AM, WATSON M, CREANOR SL, FOYE RH. The $p \mathrm{H}$ and titratable acidity of a range of diluting drinks and their potential effect on dental erosion. J Dent. 2002; 30:313-317.

5. COSTA CC, ALMEIDA ICS, COSTA LC., Filho Erosive effect of antihistamine-containing syrup on primary enamel and its reduction by fluoride dentifrice. Int J Paediatr Dent. 2006; 16:174-180.

6. De WITTE AMJC, De MAEYER EAP, VERBEECK RMH. Surface roughening of glass ionomer cements by neutral NaF solutions. Biomaterials. 2003; 24:1995-2000.

7. JAEGGI T, GRUNINGER A, LUSSI A. Dental erosion. Monogr Oral Sci. 2006; 20:200-214.

8. PRAKKI A, CILLI R, MONDELLI RFL, KALACHANDRA S, PEREIRA JC. Influence of pH environment on polymer based dental material properties. J Dent. 2005; 33:91-98.

9. SIDERIDOU I, TSERKI V, PAPANASTASIOU G. Effect of chemical structure on degree of conversion in light-cured dimethacrylate-based dental resins. Biomaterials. 2002; 23:1819-1829.

10. SILVA RC, ZUANNON ACC. Surface roughness of glass ionomer cements indicated for atraumatic restorative treatment. Braz Dent J. 2006; 17:106-109.

11. TURSSI CP, HARA AT, SERRA MC, RODRIGUES AL., Jr Effect of storage media upon the surface micromorphology of resin-based restorative materials. J Oral Rehabil. 2002; 29:864-871.

12. WONGKHANTEE S, PATANAPIRADEJ V, MANEENUT C, TANTBIROJN D. Effect of acidic food and drinks on surface hardness of enamel, dentine, and tooth-colored filling materials. J Dent. 2006; 34:214-220.

$\overline{\text { Manuscript received: } 06.06 .2020}$ 